\title{
Discussion on the Innovation of Humanistic Quality Education of adolescent athletes in china
}

\author{
Zhang Fan * \\ Department of Police Skills and Tactics, Nanjing Forest \\ Police College \\ Sports Science postdoctoral programme, Nanjing Normal \\ University \\ Nanjing 210023, China \\ zhangfan@nfpc.edu.cn
}

\author{
Zhou Bo \\ Department of Police Skills and Tactics, \\ Nanjing Forest Police College \\ Nanjing 210023, China \\ zhoubo@nfpc.edu.cn
}

\author{
Jia Changzhi \\ Department of Police Skills and Tactics, \\ Nanjing Forest Police College \\ Nanjing 210023, China \\ jiachangzhi@nfpc.edu.cn
}

\begin{abstract}
On the basis of discussing the existing problems of the humanistic quality of Chinese adolescent athletes, this paper puts forward the reasonable concept and method of humanistic quality education for adolescent athletes. Through literature, expert interviews, logical analysis, analysis of the existing problems of humanistic quality of adolescent athletes, rational cognition of humanistic quality education for adolescent athletes and the function of growing. As a matter of fact, in the training process of adolescent athletes, sports schools often only pay attention to the training of "champion", neglecting the cultivation of "educating people". Although it plays an important role in the rise of China's competitive sports in a short time, the painful prices of this "gold medal" pursuit are more and more criticized, and many negative phenomena of it become increasingly prominent, such as athletes' moral accomplishment, professional accomplishment and social problems caused by lacking social survival ability. Our findings indicate that innovation of education of humanistic quality can promote the coordinated development for adolescent athletes' body, heart, skill and ability.
\end{abstract}

Keywords-Humanistic Quality, adolescent athletes, training concept, interaction education, sport training

\section{INTRODUCTION}

As China's social development appears to be "new normal", faced with the situation in which the short-term talent training mode of competitive sports cannot be fundamentally reformed, in recent years, the subject of various competitive sports (" National Base for adolescent athletes" certificated by the General Administration of Sport of China according to the cycle of the Olympic Games) has also met problems when it attempts to optimize the traditional concepts of training through the "minor adjustments". Especially the traditional concept of weakening the subject spirit, the value of life and other humanistic qualities has not fundamentally changed, resulting the lack of the athletes' moral accomplishment, professional quality and other capacities, and also continuing to extend some negative social impacts. Since the "new normal" puts emphasis on the development of things' transforming "from high-speed to medium-high-speed" in terms of the speed, and changing "from elements-driven to innovation-driven" in terms of the power, as well as "the continuous optimization and upgrading of the structure", it is a irresistible tread for competitive sports' talent training to carry out the scientific and sustainable development. Excellent athletes should not only have good competitiveness and excellent practical abilities, but also have excellent humanistic quality which plays a vital role in their occupational success $[1,2]$. However, the humanities quality education is a longterm, systematic project. Besides, the adolescent athletes have not formed their world outlook, outlook on life, values; their psychology, thought as well as other aspects may also change easily. Therefore, the reserve talent training of competitive sports calls for humanistic quality education.

\section{The PROBLEMS EXISTING IN THE TRAINING OF ADOLESCENT ATHLETES}

In recent years, although our country has made great achievements in athletic sports, we should be conscious of the symbolic meaning of "gold medal" and rationally treat the problems and shortcomings of it. According to the relevant researches, we can find that the fundamental crux of preventing China's competitive sports from benign development is the phenomenon of putting the cart before the horse in the process of adolescent athletes training; that is, sports schools focus on such dominant and volatile quantitative parts as improving athletic performance, breaking records and creating gold medals, while they neglect such hidden and stable parts as adolescent athletes' individual 
needs, social development needs, sports' self-improvement needs, etc., which play the decisive role behind the "gold medal".

\section{A. The contradiction between practicing the value of the times and the conservative ideas.}

With the change of social development mode in recent years, the following characteristics are embodied: the emphasis on speed-from high-speed growth to medium and high speed growth, the emphasis on the continuous optimization and upgrading of the social and economic structure, and the emphasis on power-from factor driven, investment driven to innovation driven. What follows is that, to a certain extent, the functions, the status and the roles of sports schools must be profoundly changed to adapt to the rapid changes of the external environment. In the past, the cultivation of adolescent athletes was mainly about competitive sports, in order to win the gold medal and win the glory for the country [3]. Although it also advocated the comprehensive training, in the implementation process, it only steeled requirements on athletic performance and culture education was the flexible setting because of the unlimited expansion of the gold medal, which caused that cultural learning and quality education had been marginalized for a long time. In the scientific and pluralistic society, the value orientation of this kind of inertia does not accord with the law of young people's success, nor is it agreed and accepted by the society and family. As a result, more and more parents are opposed to children's participation in physical training, resulting in losing a large number of talented people who have sports potential.

\section{B. The contradiction between improving the quality of running schools and the experienced teaching teams.}

Because the sports training of athletic schools has the distinct characteristic of "experience-guiding-practice", its inevitable subjectivity will make the teaching teams have outof-place understanding, non-objective positioning, and inaccurate sports laws as well as laws of Education. Therefore, in the past, improving the performance of training might only be a slogan. Especially in the new situation, if only with the original experiences and traditional training methods, lacking rational, scientific and innovative consciousness, it will be difficult to make sports training move to a higher level, and will also exist greater blindness and risks in the adolescent athletes training [4,5]. What's worse, it will not only result in a great deal of waste of people, money and things and lowlevel redundant construction, but also bring serious pressure and burden to the society and family, and make social competition of sports schools decline constantly and enter a vicious circle.

\section{The contradiction between changing the development mode and the traditional training mode.}

During a long time, the training of competitive adolescent athletes is still dominated by the "one-stop" and "single" mode. It not only causes the adolescent athletes training mode of "management of the whole nation system, profession of the amateur system ", but also causes that athletes' cultural learning and quality education have always been outside the education system, and they can not enjoy the high-quality educational resources and the protection of the basic rights and interests of the people. In addition, the contradiction between the high risk and high elimination of competitive sports and the serious vacancy of career planning directly leads to it that the phenomenon of "the darling of the project and the changeling of the society" emerges in an endless stream. The current training model is the fundamental reason for the weakening of schools' running function and the reduction of its scale.

\section{The contradiction between satisfying social demands and the single specialty.}

It is a basic, strategic and long-term systematic project to cultivate adolescent athletes in competitive sports, which not only needs to regard winning glory for the country as the highest form of expression, but also needs to maximize the value of the individual athlete. Therefore, we should attach the same importance to the positioning of the individual athlete's sports career as well as the planning and development of his social career. However, the current "single, closed and extensive" training mode is divorced from the track of social development, and does not understand the guideline of "people-oriented and comprehensive training" advocated by the state, which only focuses on the surface of the operation, without paying attention to the training process and the evaluation of social benefits. Especially in the process of running schools, the ideologies of "playing for medals" and "quick success " have not been fundamentally reversed and curbed. These are the contradictions and problems that need to be solved urgently.

\section{RATIONAL KNOWLEDGE OF HUMANISTIC QUALITY EDUCATION}

Humanistic quality refers to the spiritual character of becoming men and the development degree of being talents, including the behavioral tendencies, moral character, cultural accomplishment and aesthetic taste. It is a kind of effort for the athletes to observe the morality of aesthetics, to pursue the spiritual civilization and to improve themselves in the process of the competitive sports' learning, training and competition. Combining it with physical quality, technical and tactical quality, psychological quality as well as intelligent quality, forms the athletes' accomplishment of athletics which is actually the requirement for "people's" all-round development. Because the subjects of competitive sports are athletes, as social men, they must have the people's social attributes, which requires the strengthening of humanistic quality training on adolescent athletes, so that they can achieve all-round development in the future. However, many evidences show that the current training of adolescent athletes is the lack of humanistic quality education, which has affected the transition from "ideological formation" to "gradually fixed ideology". It has caused negative impacts on the growing youth. Therefore, the adolescent athletes training should not only take into account the requirements of future career for sports skills, but also fully consider whether their comprehensive quality meets the needs of society. 
The important goal of humanistic quality education is to help the adolescent athletes form the correct world outlook, outlook on life, values, morality and aesthetics, so that they can learn to distinguish the rights from wrongs. The questions about the meaning of human life are included, such as what people live for, why they engage in competitive sports, why people need to work with others in the team, what is the real success and what qualities needed to become excellent athletes. The adolescent athletes are not only in the growth period physiologically, but also during the period when they form their characters, world outlook, outlook on life and values [6]. As the educator Huang Yanpei said: "I feel the most difficult period is in middle school. When in university, people's outlook on life is gradually identified. Primary school is the cross of the road, so people may be dramatically different." At this stage, the importance to carry out humanistic quality education on the adolescent athletes is obvious because there is a close relationship between the humanistic quality and sports spirit. In nature, the humanistic quality and sports spirit both come from spiritual influence which targets at not only knowledge, but also the spirit. Hence, the competitive sports can provide the adolescent athletes with the world they can learn from and offer them the moral judgments, value orientation, a way of thinking and the spiritual ideas.

\section{INNOVATION OF EDUCATION OF HUMANISTIC QUALITY OF ADOLESCENT ATHLETES IN CHINA}

In the training process, the adolescent athletes should not obtain excellent athletic performance at the expense of ideas, culture, psychology, ability and other quality education. The competitive sports cannot ignore that adolescent athletes are thoughtful, emotional, biological individuals and the competitive sports should be based on humans, with the purpose of the "all-round" development of the adolescent athletes and sticks to the humanistic quality education.

\section{A. Remolding training concept}

The adolescent athletes are not only the "playwrights" of sports, but also the "participants" of the society as well as the "representatives" of the competitive sports so they combine knowledge, love, meaning and action. Therefore, it is necessary to strengthen the humanistic quality education on the basis of the existing sports training, freeing from the limitations and one-sideness of the single talent training mode. The humanities quality education should be greatly strengthened, to make the adolescent athletes become people of all-around development with the truth, goodness and beauty as well as knowledge, skills and attitudes. To analyze from the essence, the effects of education on human development are gradually achieved mainly through the humanistic quality education. A Bad combination of two kinds of education, especially in the field of competitive sports, will lead to the gradual loss of outstanding morality and ideology as well as the sense of mission in the adolescent athletes so that their foundation for career will not be stable enough and lack of long-term stable power. Therefore, the utilitarian of competitive sports should be changed and the principle of paying equal attention to sports training and humanistic quality education should be followed. Besides, the reform of competitive sports' adolescent athlete training model should be strengthened, to change the past opinion of "focusing more on matter than people" and "paying attention to athletic performance but neglecting humanistic quality education. So the value adolescent athletes are built, with "humanistic quality education coming first"

\section{B. Promote interaction between learning and training}

1) Good combination between culture teaching and sports training. Because of the particularity of the adolescent athletes training, it is with unique advantages to carry out humanistic quality education in the process of sports training. However, most of the previous research is confined to the classification of culture teaching or sports training while the research on how to achieve the best combination of two carriers of education and how to make interaction are still wanting. At present, there are some unavoidable problems in the practice of combining humanistic quality education in culture teaching and sports training [7]. For example, the sports training has great impacts on culture teaching and what is learned in culture teaching cannot be fully used or practiced in sports training. Such problems seem to be derived from the "conflicts between the sports training and the culture teaching" but in essence they are the problems due to the failure in the effective combination of cultural teaching and sports training. The best combination of culture teaching and sports training is a systematic project, and is in an interactive dynamic process. In the external form, they perfectly combine and affect as well as promote each other through certain intermediary organizations (internal functional departments and external interdepartments). In terms of the internal mechanism, it is needed to take the adolescent athletes as the subjects, to promote the human knowledge and information to be interacted between the culture teaching and sports training through acceptance, collection, integration, and feedback; in the operation process, the combination between the representation of culture teaching and the expansion of sports training should be improved.

2) The positive Interaction between Teachers of Literary Class and Sports Coaches. It's worth considering that the adolescent athletes were not only the sportsmen, they were also the young students in the crucial stage of physical and mental development [8]. Without the vision of the long-term development and behavioral biases, the attention to the present interests alone would lead to a relatively short sporting life of adolescent athletes who had excellent achievements in sports competition while having a lower humanities quality and culture knowledge. They couldn't become excellent athletes and top sports talents for the lack of good humanistic qualities and integrated personalities. In order to tackle this problem, the performances reflecting the comprehensive development of adolescent athletes in sports competition, the literary class and humanistic quality evaluation should be jointly combined and converted into evaluation system so as to urge the teachers of literary class and sports coaches to cooperate with each other and strengthen the humanistic quality education of the 
adolescent athletes. Moreover, the interactive evaluation mechanism on the basis of trust, responsibility and honesty ought to be established and continuously improved to ensure the reciprocal interaction between teachers of literary class and sports coaches in training the athletic adolescent athletes.

\section{SUMMARY}

From historical experiences, we can conclude that, in the development of competitive sports, if we ignore the link of "educating people", people we train may be the imperfect "social man", and competitive sports will not make a qualitative leap. Therefore, we should pay attention to the subjects' cultivation of humanistic quality education, start from the basic part and develop the rich cultural soil for competitive sports, so as to promote the coordinated development for adolescent athletes' body, heart, skill and ability. Finally, at least under the current training mode, whatever they become the elite athletes or take up other jobs in the society in the future, the mode will help them make the correct values, norms of behavior pattern, refresh themselves, lay a solid foundation and move forward.

\section{ACKNOWLEDGMENT}

This work was supported in part by the Project of the Fundamental Research Funds for the Central Universities under Grant LGZD201709, in part by the Project of China Postdoctoral Science Foundation under Grant 2017M611849, in part by Jiangsu Qing LAN Project under Grant 2017, and in part by Nanjing Forest police College Teaching Reform Project under Grant ZD17001 \& YB17001.

\section{REFERENCES}

[1] ZHU Jie, ZHANG Fan, WANG Changsheng, et al. Construction of the Influential Factors Model for the Deviation of Humanistic Quality of Athletic Reserves in China. Journal of Guangzhou Sport University. Vol. 36 (2016) No. 6, p. 15-22

[2] WANG Xianghong, LI Yepeng. The Educational Pattern of Chinese Competitive Sports School Attached to PE Universities and Institutes. Journal of Capital College of Physical Education. Vol. 23 (2011) No. 5, p. $402-404$

[3] LIU Zhiyun, WANG Xiaofen, WANG Weiming, et al. The Research on the Developing directions of the Cultivating System of Competitive Reserved Talents in China. Journal of Tianjin University of Sport. Vol. 24 (2009) No. 1, p. 85-88

[4] WAN Bingjun. Green Training Concept for Athletes - Humanistic Concerns Based on Philosophy of Technology. China Sport Science. Vol. 32 (2012) No. 7, p. 78-84

[5] CHENG Jia, ZHAO Guangyu, WU Xin, et al. In the Development of Science Curriculum Efforts Should Be Made to Explore Teaching Materials with Humanistic Concerns and of Help to the Cultivation of Humanism.Journal of The Chinese Society of Education. Vol. 19 (2007) No. 7, p. 46-48

[6] SHI Y.J. Humanistic quality theory. People's University of China press, 2008, p. 21-22

[7] GU Dehong. Logical Starting Point of Transforming the Development Mode of Competitive Sports in China. Journal of Tianjin University of Sport. Vol. 30 (2011) No. 5, p. 383-387

[8] LI Chunhui. Connotation and Characteristics of Sports Culture and Sports Humanistic Spirit Construction in Contemporary China. Journal of Beijing Sport University. Vol. 38 (2015) No. 12, p. 22-26 